\title{
Uso de HQS como ierramenta motivacional para o ensino de Astronomia
}

Marcia Helena Ribeiro

$<$ https://orcid.org/0000-0002-6846-5758> Instituto Federal de Mato Grosso do Sul / Coxim [MS] Brasil

André Munhoz de Argollo Ferrão

$<$ https://orcid.org/0000-0003-0687-3622> Universidade Estadual de Campinas / Campinas [SP] Brasil

RESUMO

O Universo é algo que sempre chamou a atenção da humanidade e talvez por isso a Astronomia é uma das ciências mais antigas da história. Contudo, o ensino e aprendizagem dessa disciplina esbarram em algumas dificuldades devido a uma certa insegurança por parte dos professores e pela falta de um material lúdico apropriado para trabalhar o conteúdo com crianças e adolescentes. Assim, este estudo apresenta os resultados de uma pesquisa junto aos estudantes de escolas do Ensino Fundamental do município de Coxim [MS], por meio do uso de História em Quadrinhos (HQs) elaboradas em "tirinhas" como forma de verificar a sua potencialidade como ferramenta motivacional para o ensino e aprendizagem dos temas que envolvem o Universo e a Terra. Para tal, foram aplicadas avaliações, no início e no final de uma sequência de ensino, elaboradas para trabalhar o tema em questão. Evidenciamos que o uso de HQs como ferramenta motivacional apresentou resultados positivos para o ensino de Astronomia junto aos estudantes do Ensino Fundamental.

PALAVRAS-CHAVE

História em Quadrinhos. Astronomia. Eclipse Solar. Eclipse Lunar.

\section{Using Comics as motivational tool for teaching Astronomy}

\begin{abstract}
The Universe is something that has always caught the attention of mankind and has given rise to Astronomy, which is one of the oldest sciences in our history. However, teaching and learning this content comes up against some difficulties on the part of teachers' insecurity and differentiated material to work on this content. Thus, this study presents the results of a survey with students from elementary schools in the city of Coxim [state of Mato Grosso do Sul, Brazil] through the use of a Comic Book elaborated in the form of comic strips as a way of verifying its potential as a motivational tool for the teaching and learning processes about the subjects that involve the Universe and the Earth. To this end, evaluations were applied at the beginning and at the end of a teaching sequence designed to work on the topic in question. We evidenced that the use of Comics as a motivational tool presented positive results for teaching Astronomy, particularly with the students of the Elementary School.
\end{abstract}

KEYWORDS

Comics. Astronomy. Solar Eclipses. Lunar Eclipses. 


\section{Introducão}

O Universo é algo que sempre encantou e impressionou a humanidade. Desde a pré-história o homem busca por uma explicação do que vemos acima de nossas cabeças. Tentar desvendar os seus mistérios não é algo novo, pois desde que o homem habitava as cavernas, já havia uma necessidade de explicar essa imensidão do espaço (Amaral, 2008).

Vários filósofos e pensadores da antiguidade foram motivados a fornecer explicações a respeito do Universo. Em princípio elas se restringiam a descrever o Sol, a Lua e alguns planetas. Somente após o aprimoramento da luneta e do telescópio é que ocorreu uma expansão desse conhecimento. Atualmente, não só o Sistema Solar é pesquisado, mas também estrelas e galáxias (Milone et al., 2018).

A ciência que estuda o Universo recebe o nome de Astronomia. Essa é uma das ciências mais antigas da Humanidade. Ela consegue despertar o interesse não apenas de adultos, mas também de crianças por esclarecer as curiosidades e os questionamentos que envolvem o espaço (Bonfleur et al., 2007).

Apesar de ser uma ciência antiga, a Astronomia ainda se encontra distante das salas de aulas. Despertar nos estudantes o conhecimento para essa ciência envolve uma grande quantidade de outras áreas tais como: Geografia, História, Mitologia, Física, Biologia, Química etc. (Amaral, 2008).

Segundo Amaral (2008), essa gama de conhecimentos necessários para uma abordagem do conteúdo de Astronomia possa ser um dos fatores para esse conteúdo ser pouco explorado nas escolas e, principalmente, no Ensino Fundamental. Também os cursos de licenciatura, com formação para o ensino de ciências, não fornecem a qualificação necessária para o professor trabalhar com propriedade, esse conteúdo. Também existe a questão do material didático. No Ensino Fundamental o conteúdo de Astronomia, na maioria dos casos, só aparece no final do livro, fazendo com que muitas vezes não seja abordado em sala de aula.

De acordo com as orientações contidas na Base Nacional Comum Curricular (BNCC), Brasil (2018), a Astronomia é um conteúdo que deve ser abordado na Educação Básica, principalmente junto aos estudantes do Ensino Fundamental, como forma de promover uma compreensão do lugar que ocupamos no espaço e ainda indica que, o uso de novas ferramentas pode promover uma maior motivação na aprendizagem dessa ciência.

Nesse sentido, Palhares (2008) sinaliza que o profissional da Educação procura desenvolver novas metodologias de ensino que possam contribuir para uma melhoria no processo de ensino/aprendizagem. Assim, o professor de ciências vem utilizando a HQ como uma ferramenta alternativa para suas aulas, tendo em vista que os estudantes estão cada vez mais em contato com imagens, o que facilita um recebimento de forma rápida do conhecimento.

A comunicação por meio de imagens foi algo de que a humanidade sempre necessitou, pois desde a época que o homem morava nas cavernas, a imagem serviu como fonte de informação. Desta mesma forma, atualmente, a HQ tem um papel importante na formação de jovens e adultos (Carvalho et al, 2009).

Por possuírem a capacidade de prender a atenção do leitor e possibilitar uma forma variada de temas, as HQs podem abarcar vários assuntos do cotidiano relacionados à política, cultura, meio ambiente, inclusive ser aplicada em material didático (Massuda, 2011).

Quanto à sua aplicação em materiais didáticos, Testoni (2004) apresenta quatro categorias das HQs: a) ilustrativa: usado para retratar um assunto previamente estudado; b) explicativa: explicação de um fenômeno físico por meio do enredo de uma HQ; c) motivadora: utilizado como forma de instigar o estudante a pesquisar o tema abordado; d) instigadora: usado antes da abordagem de um conteúdo com a finalidade de estimular o aluno a pensar a respeito do assunto a ser trabalhado.

Nesse sentido, apresentamos os resultados de um estudo realizado junto aos estudantes do Ensino Fundamental de escolas do município de Coxim-MS, por meio da aplicação de uma sequência de ensino com o uso de uma História em Quadrinhos (HQ) elaborada e criada para verificar o seu potencial como ferramenta motivadora para o ensino de Astronomia. 


\section{Labor \& Engenho}

\section{Material e Métodos}

\subsection{ELABORAÇÃO DAS “TIRINHAS”}

As tirinhas foram elaboradas e criadas em dois diferentes grupos: um grupo para abordar os conceitos relativos ao Sistema Solar e outro para trabalhar os fenômenos que ocorrem entre o Sol, a Terra e a Lua. O grupo do Sistema Solar somou um total de dez tirinhas que abordaram cada um dos planetas desse sistema, os cometas, o Sol e demais astros. O segundo grupo, no total de cinco tirinhas, abordou os fenômenos como: Dia e Noite, Fases da Lua, Eclipses, Estações do Ano e Fenômeno das Marés.

As falas dos astros foram elaboradas em uma linguagem simples, de fácil leitura e interpretação, ou seja, uma linguagem própria das HQs.

Para a elaboração da arte final do desenho foi contratado o cartunista Rafael Ghiraldelli, quem, sob orientação da pesquisadora Marcia Ribeiro, elaborou os desenhos dos astros de maneira personificada, como forma de atrair a atenção dos estudantes.

Com o objetivo de facilitar a leitura e visualização dos balões, as tirinhas ocuparam uma folha de papel A4.

A Figura 1 apresenta uma das tirinhas elaboradas para aplicação da sequência de ensino em escala adaptada ao tamanho da página da Labor \& Engenho. A tirinha da Figura 1 aborda o fenômeno dos eclipses solar e lunar.

Figura 1. Eclipse Solar e Lunar. Habilidades trabalhadas de acordo com a BNCC, Brasil, 2018:

(EF08C112) Justificar, por meio da construção de modelos e da observação da Lua no céu, a ocorrência das fases da Lua e dos eclipses, com base nas posições relativas entre Sol, Terra e Lua. (EF08C113) Representar os movimentos de rotação e translação da Terra e analisar o papel da inclinação do eixo de rotação da Terra em relação à sua órbita na ocorrência das estações do ano, com a utilização de modelos

ridimensionais. Assuntos abordados: movimento de translação da Terra e da Lua; sombra e penumbra; posição dos astros para ocorrência de eclipse Fonte: a autora. Desenho: Rafael Ghiraldelli-ghiralds@gmail.com.
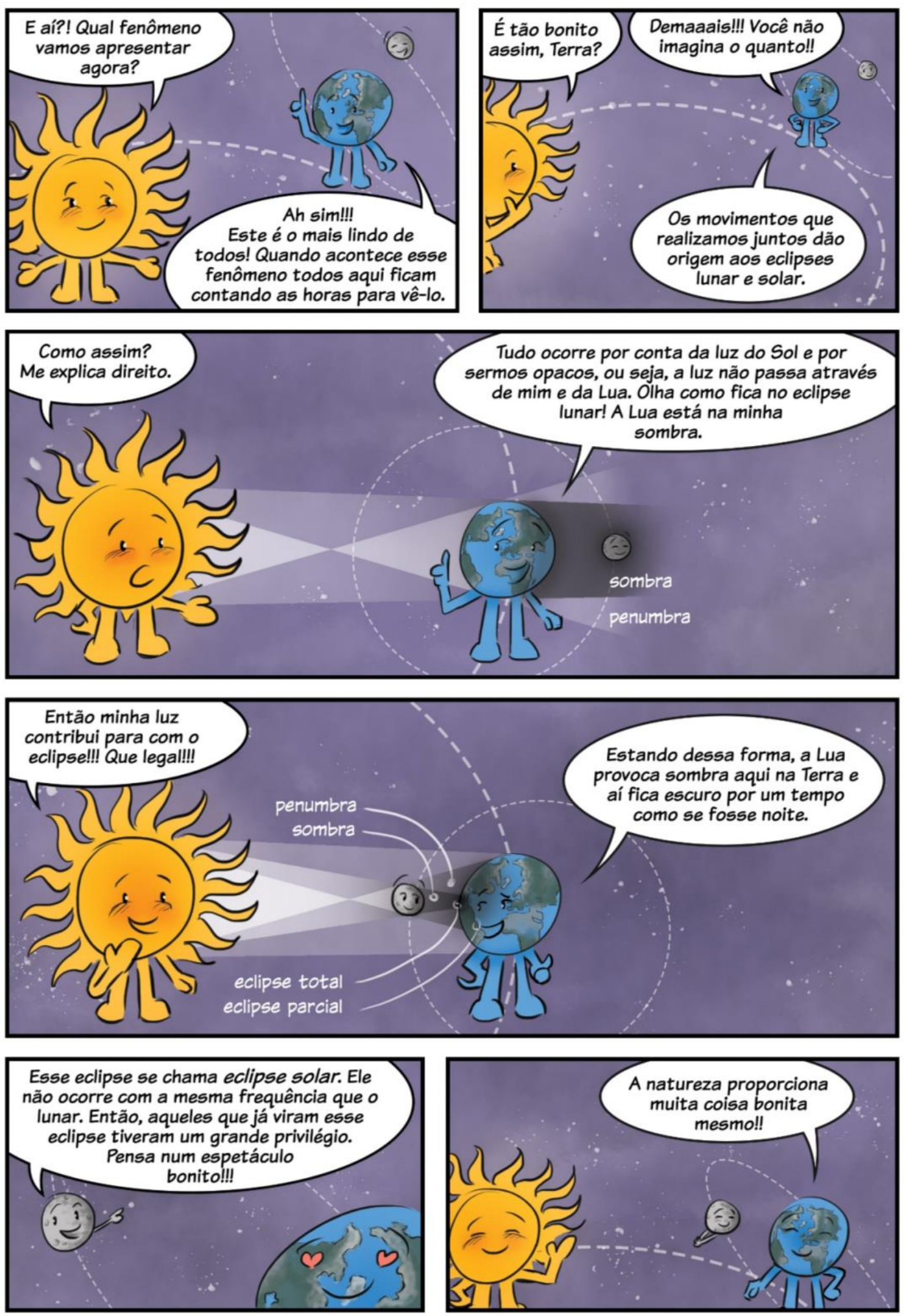

Labor \& Eng., Campinas, SP, v.14, 1-9, e020012, 2020 - ISSN 2176-8846 


\subsection{OS INSTRUMENTOS DE AVALIAÇÃO}

Como forma de verificação da assimilação dos conceitos de Astronomia abordados durante a sequência de ensino, foram elaboradas duas avalições: Avaliação Diagnóstica Inicial e Final. As duas avaliações contaram com as mesmas questões para que ao final do estudo fosse possível fazer uma comparação desses dois instrumentos e, assim, verificar se houve ou não uma assimilação dos conceitos.

\subsection{A SEQUÊNCIA DE ENSINO}

Para a aplicação da sequência de ensino foram necessárias 6 aulas de 50 minutos cada uma, assim distribuídas: 1 aula para aplicação da Avaliação Diagnóstica Inicial, 4 aulas para trabalhar o conteúdo usando a HQ para introdução de cada tópico trabalhado e 1 aula para aplicação da Avaliação Diagnóstica Final.

A pesquisa foi desenvolvida em 03 escolas do Ensino Fundamental do município de Coxim-MS. Por questão de ética o nome das escolas não será divulgado e sim, para sua identificação foram usadas 02 letras maiúsculas aleatórias para designação de cada uma (PC, W'T e SF).

\section{Resultados obtidos}

Aqui, apresentamos os resultados obtidos com a aplicação da tirinha relativa à ocorrência dos eclipses solar e lunar realizada junto aos sujeitos da escola WT.

A Avaliação Diagnóstica Inicial contou com duas questões. A primeira procurou pelo conhecimento a respeito do Eclipse Lunar. Nessa questão, esperava-se que o sujeito fizesse um desenho indicando as posições corretas do Sol, Lua e Terra, bem como os locais de sombra e penumbra. A segunda questão buscou as mesmas informações, porém para a ocorrência do Eclipse Solar.

O gráfico da Figura 2 mostra os resultados da Avalição Diagnóstica Inicial para esse tema.

Ressaltamos que as respostas foram categorizadas em: resposta correta, Resposta parcialmente correta, resposta incorreta e resposta em branco.

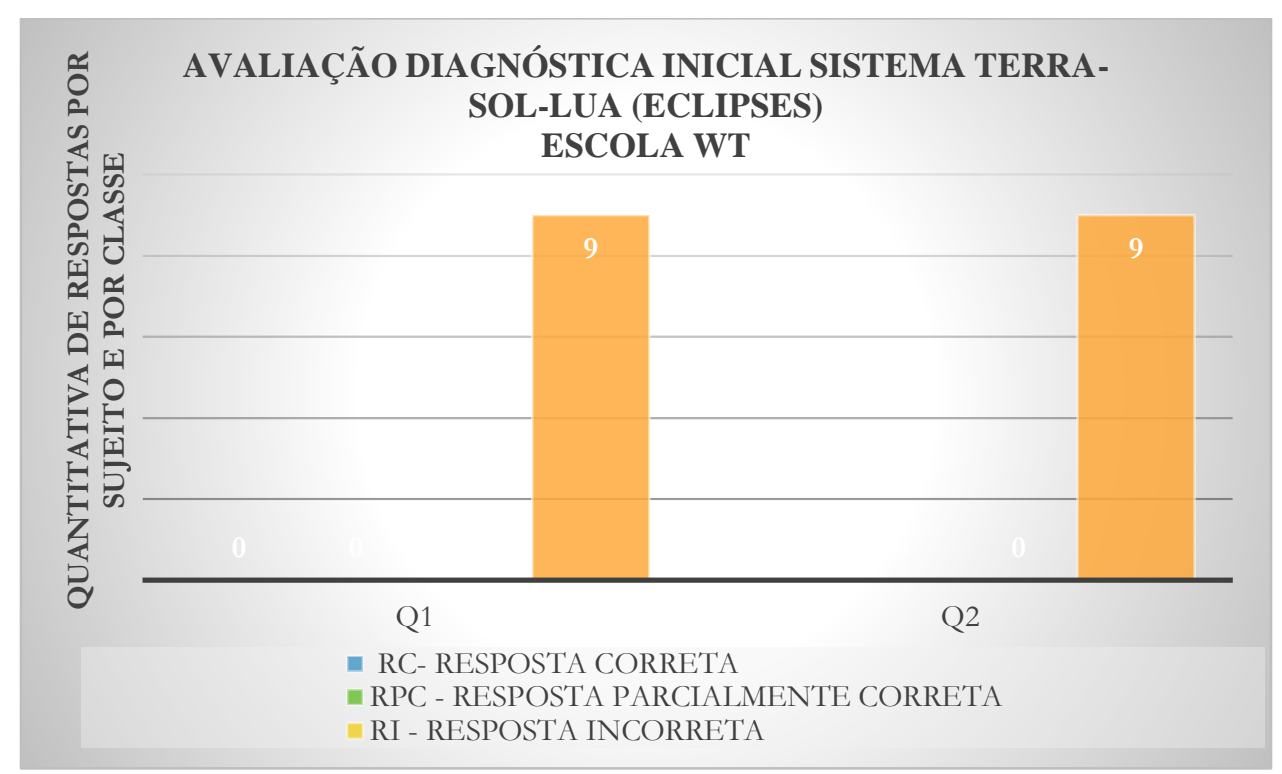

Figura 2. Gráfico do resultado da Avaliação Diagnóstica Inicial Sistema Terra-Sol-Lua (Eclipses) - Escola WT. Fonte: Os Autores.

Analisando o gráfico da Figura 2 observamos que as duas questões foram enquadradas na categoria resposta em branco. Assim, as respostas apontaram que nenhum dos sujeitos possuía o conhecimento relativo à ocorrência dos eclipses.

A avaliação Diagnóstica Final contou com as mesmas duas questões da inicial com a finalidade de se fazer uma comparação e verificar a questão de assimilação dos conceitos trabalhados e com o uso da HQ como forma de motivação dos estudantes para esse assunto. 
O gráfico da Figura 3 apresenta os resultados da Avaliação Diagnóstica Final.

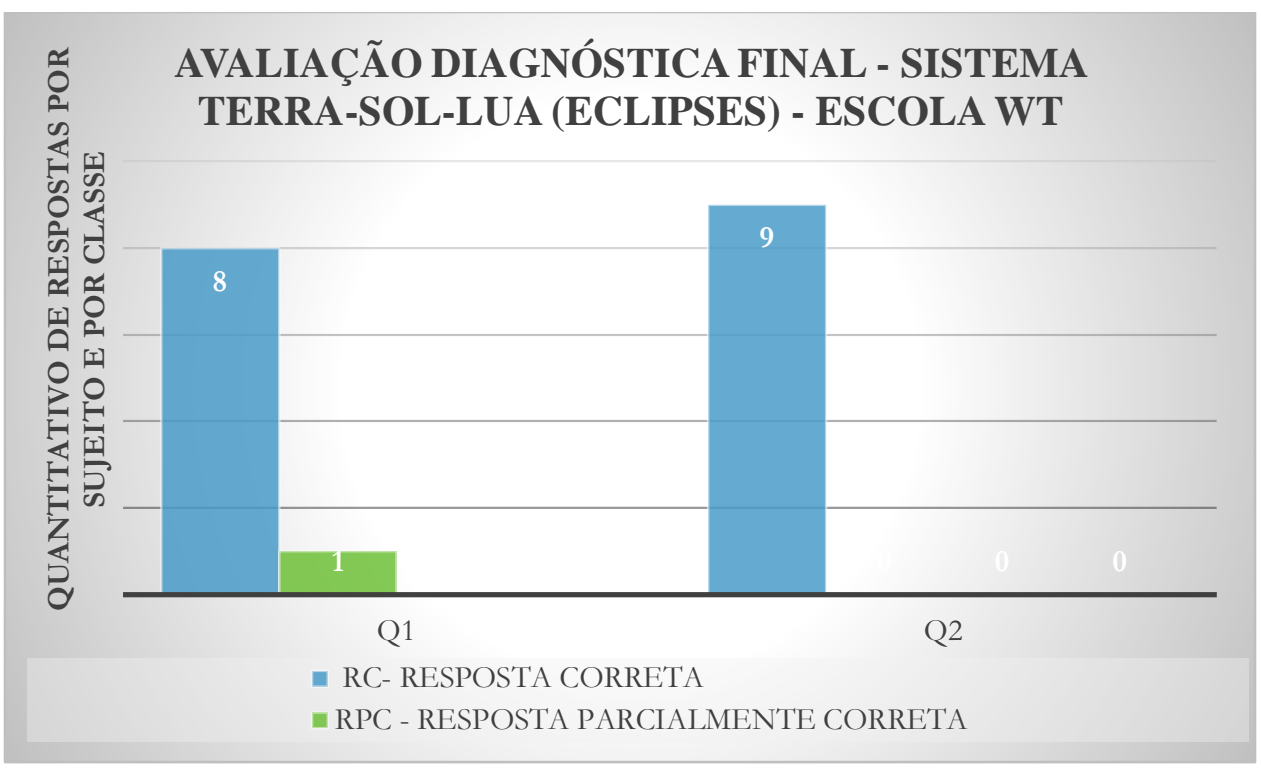

Figura 3. Gráfico do resultado da Avaliação Diagnóstica Final - Sistema Terra-Sol-Lua (Eclipses) - Escola WT. Fonte: Os Autores.

Analisando o gráfico da Figura 3, observamos que não obtivemos respostas enquadradas nas categorias: resposta em branco e resposta incorreta. Para as duas questões dessa avaliação praticamente todos os estudantes fizeram o esquema de forma correta e apenas um, de forma satisfatória, ou parcialmente correta.

\section{Discussão dos resultados obtidos}

A análise dos resultados revela que o uso de uma HQ, como elemento motivacional para introdução de conteúdos de Astronomia, levou os sujeitos participantes da pesquisa a uma melhor assimilação dos conceitos trabalhados em sala de aula, pois percebe-se, pelos desenhos apresentados pelos mesmos que o conceitos, em sua grande maioria, foram aplicados de forma cientificamente correta.

Assim, apresentamos os esquemas elaborados pelos sujeitos para a ocorrência do Eclipse Lunar e Solar após a aplicação da sequência de ensino usando a HQ.

O desenho da Figura 4 apresenta para o Eclipse Lunar a posição correta dos astros e a sombra que a Terra projeta no espaço. Foi bem representado que a sombra que a Terra projeta no espaço é bem maior do que as dimensões ocupadas da Lua. Para o Eclipse Solar, os astros também foram dispostos de forma correta, inclusive indicando o cone de sombra, a região de penumbra e os locais de eclipse total e parcial.

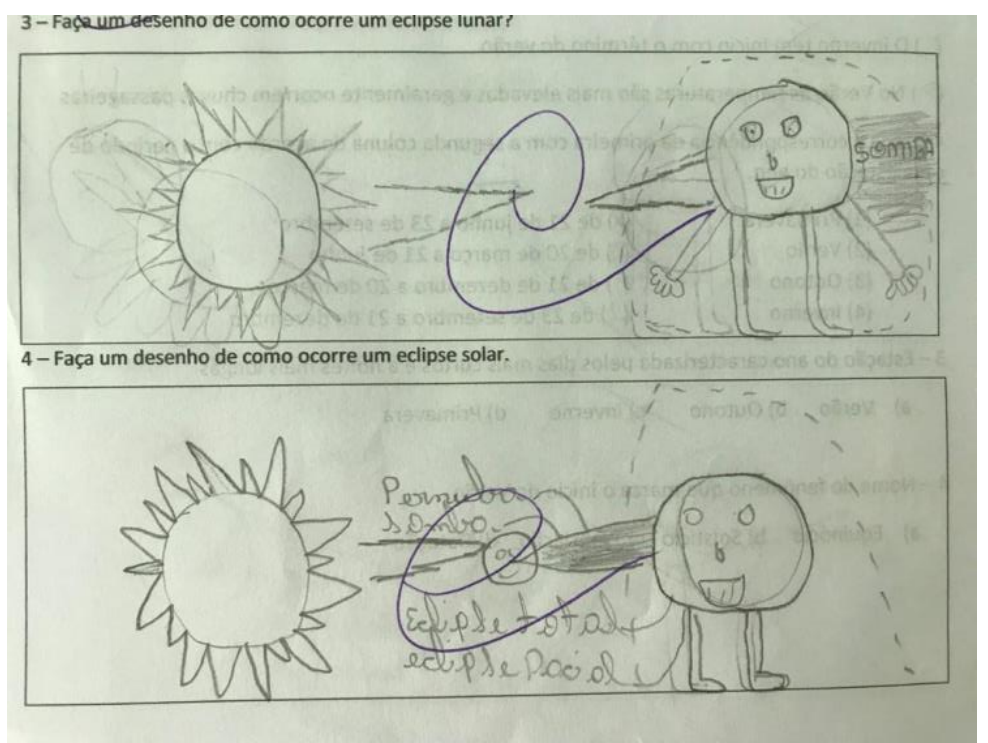

Figura 4. Desenho elaborado por um dos sujeitos participantes da pesquisa.

Fonte: Os Autores. 
Nos desenhos das Figuras 5 e 6, além de todas as informações que foram citadas pelo sujeito do desenho da Figura 4, esse sujeito ainda especificou, de forma mais clara, os astros e locais de sombra e penumbra. Estabeleceu, de maneira correta, os raios solares para projeção de sombra e penumbra, sendo que ainda colocou uma linha pontilhada indicando a órbita da Lua em torno da Terra.

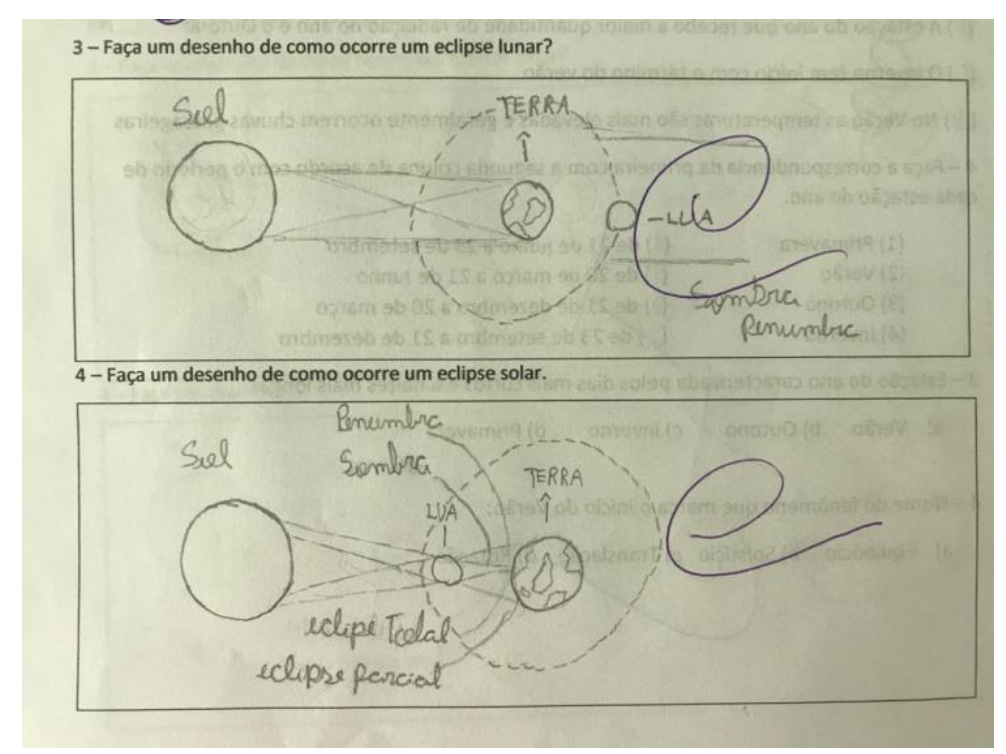

Figura 5. Desenho elaborado por um dos sujeitos participantes da pesquisa. Fonte: Os Autores.

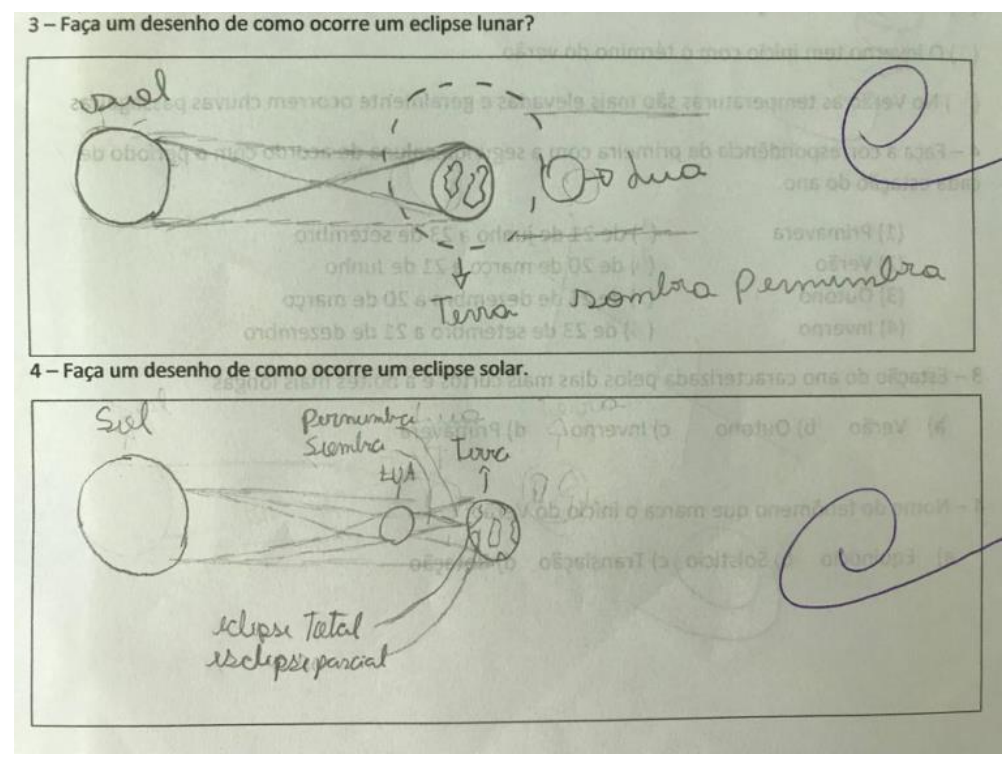

Figura 6. Desenho elaborado por um dos sujeitos participantes da pesquisa. Fonte: Os Autores.

O esquema indicado pelo desenho da Figura 7 apresentou perfeitamente as posições dos astros para ocorrência dos eclipses, incluindo local de sombra, penumbra, eclipse total e parcial. Apenas um detalhe deixou a desejar: não foi representada a trajetória da lua, mas, mesmo assim, pode-se considerar que foi uma boa representação para os eclipses.

No desenho da Figura 8 apesar do sujeito ter apresentado entendimento da posição dos astros, falhou ao colocar o esquema do Eclipse Lunar no lugar do esquema do Eclipse Solar e vice-versa. Também deixou a desejar, no primeiro esquema, em que apresenta a luz partindo também da Lua e divergindo para a Terra. Dessa forma, não haveria sombra e nem penumbra, porém, tendo em vista que o sujeito não havia apresentado nenhuma resposta para essa questão, entendemos que houve uma assimilação parcial do conceito.

O desenho da Figura 9 também representa bem o esquema desse fenômeno celeste. O sujeito indicou corretamente os locais de sombra, penumbra, Eclipse Solar total e parcial. Pode-se observar que houve uma assimilação dos conceitos apresentados em sala de aula. 

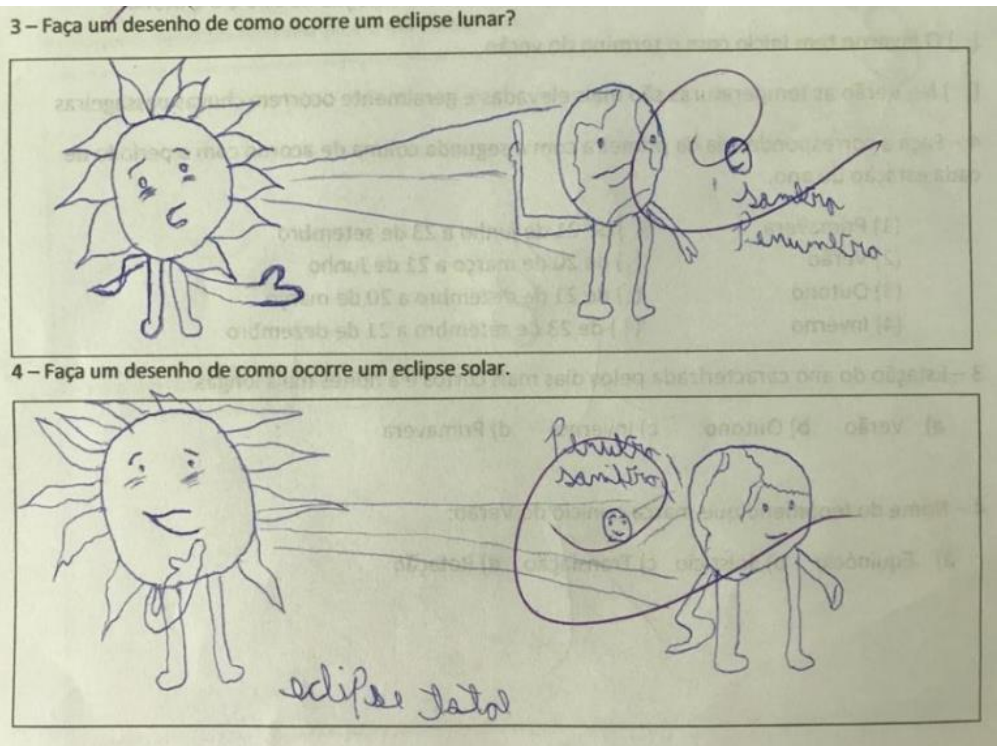

Figura 7. Desenho elaborado por um dos sujeitos participantes da pesquisa. Fonte: Os Autores.

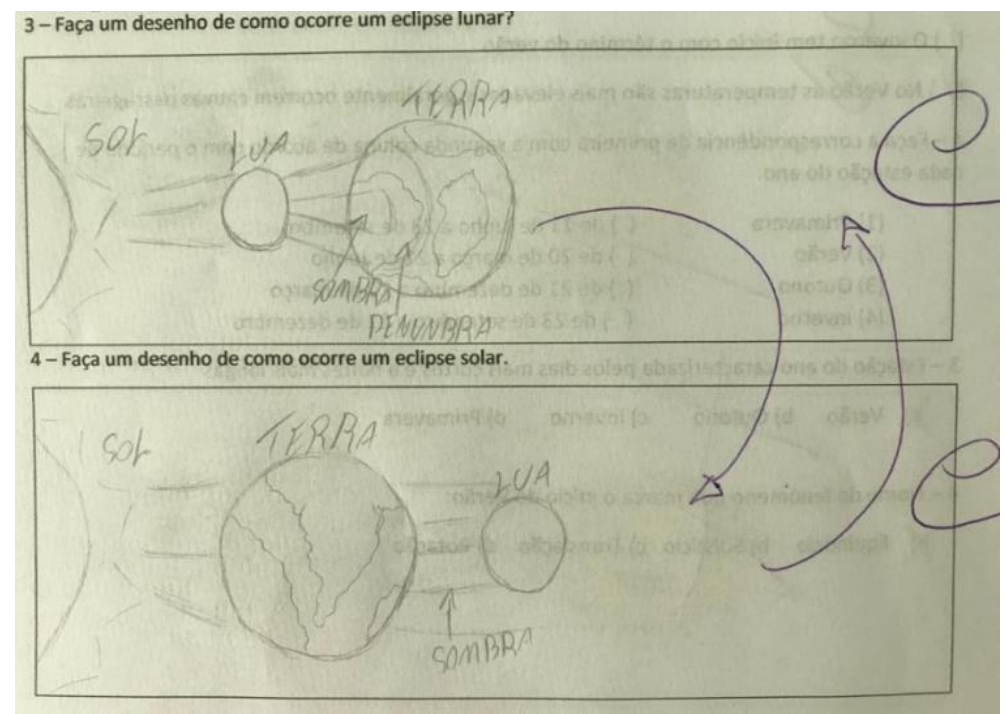

Figura 8. Desenho elaborado por um dos sujeitos

participantes da pesquisa.

Fonte: Os Autores.

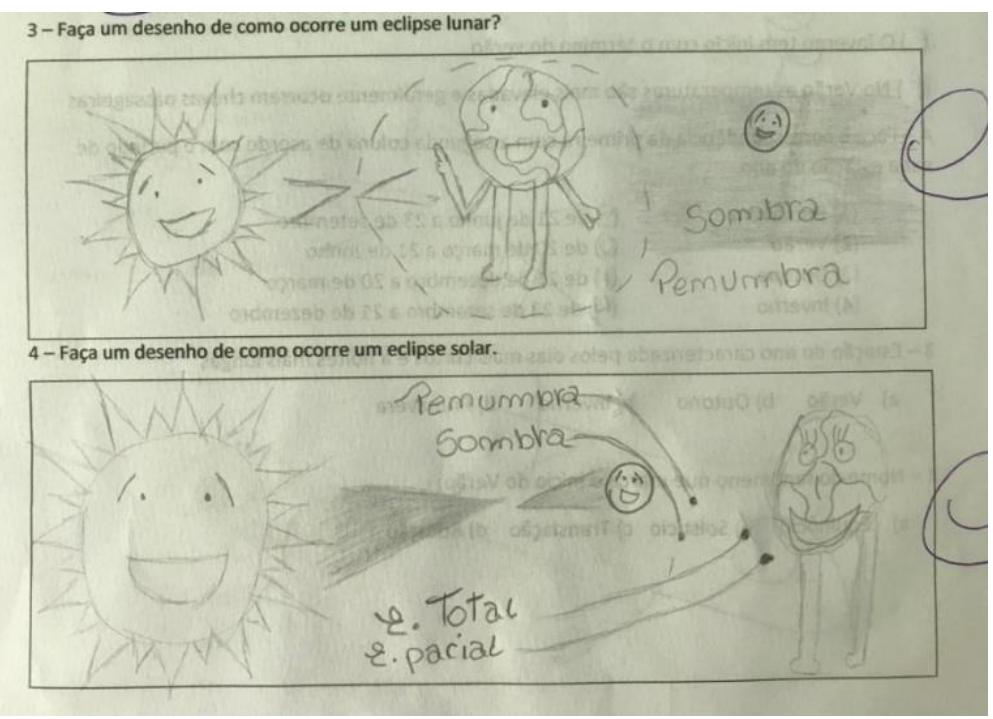

Figura 9. Desenho elaborado por um dos sujeitos

participantes da pesquisa. Fonte: Os Autores.

O desenho da Figura 10 indicou, claramente, a posição dos astros, porém apenas por desenho, não fazendo uso de palavras para explicar os locais de sombra e penumbra. 


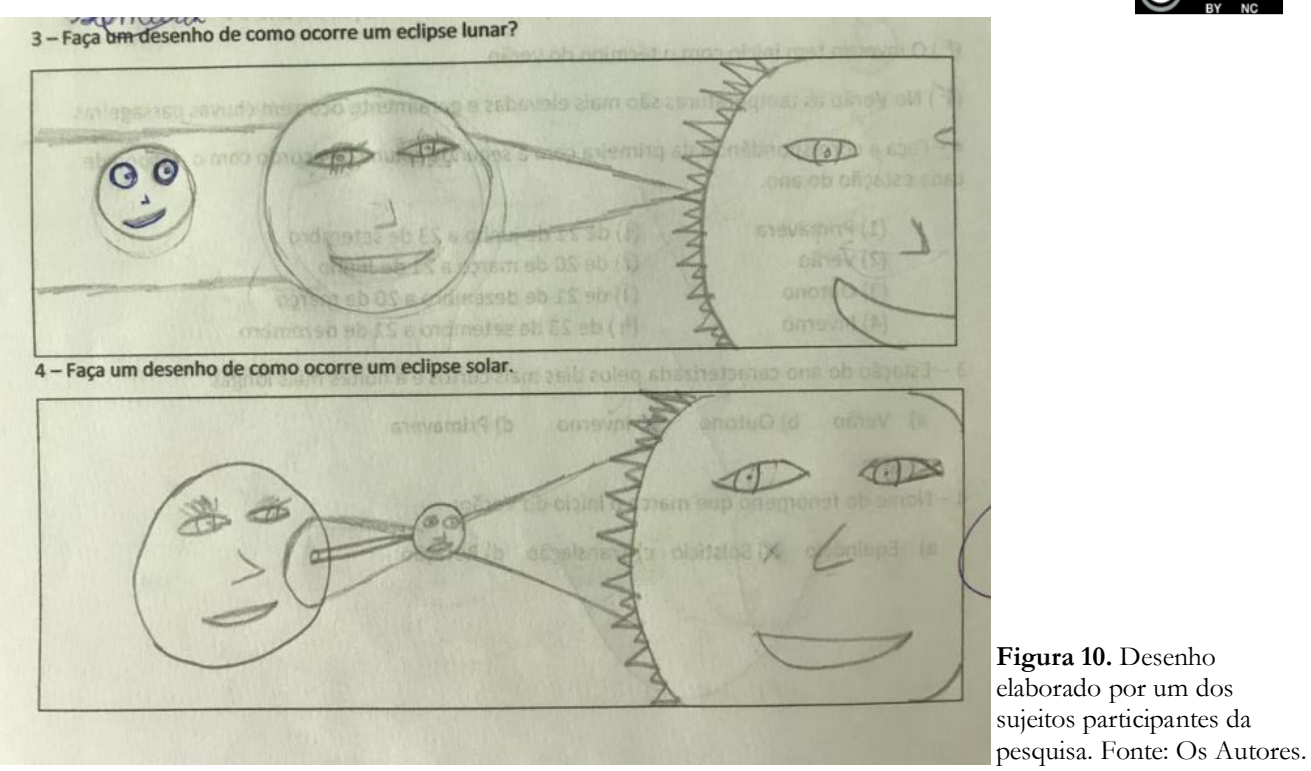

Os desenhos apontam para uma influência positiva no uso de HQs, pois todos os sujeitos apresentaram seus esquemas de forma personificada, semelhante àquela utilizada nas aulas da sequência de ensino.

\section{Conclusão}

As pesquisas realizadas para compor a revisão bibliográfica deste estudo apontaram para uma grande dificuldade por parte de muitos professores em abordar o tema Astronomia, tendo em vista uma falta de material diferenciado para se trabalhar o mesmo e a insegurança apresentada por eles com respeito ao conteúdo, em geral, superficialmente abordado nos cursos de licenciatura.

Apesar da BNCC, Brasil (2018) apresentar orientações para uma abordagem do tema relacionados à Terra e ao Universo, bem como uma indicação de uso de ferramentas diferenciadas, o conteúdo de Astronomia é pouco ou quase nunca abordado em sala de aula.

Nesse sentido, o estudo aqui apresentado indica que o uso de HQs para o ensino de conceitos de Astronomia pode promover uma assimilação de forma mais efetiva desse conteúdo, pois ao término da pesquisa, com base nas avaliações aplicadas durante a sequência de ensino, verificou-se que as HQs podem proporcionar um fator motivacional sensível aos estudantes, não só para o ensino de Astronomia, mas para o ensino de ciências de forma geral. Por ser uma ferramenta que trabalha com o visual, a HQ possibilita uma forma descontraída de incentivo à aprendizagem. Os resultados obtidos neste estudo corroboram este fato, o que permite uma recomendação positiva para o seu uso em sala de aula.

Comparando os resultados obtidos nas Avaliações Diagnósticas Inicial e Final observa-se uma indicação para aprendizagem significativa com o uso da $\mathrm{HQ}$, pois a totalidade das respostas da primeira avaliação apontou para um desconhecimento integral dos estudantes da forma como ocorrem os eclipses tendo em vista que todos os sujeitos obtiveram suas respostas classificadas na categoria resposta em branco. Porém, na avaliação final, todos os sujeitos apresentaram resultados, para as mesmas questões, de forma significativamente satisfatória.

Durante a sequência de ensino com o uso de HQs observou-se que os estudantes se apresentaram bem atentos em todas as etapas, pois estiveram quase o tempo todo envolvidos com a leitura das tirinhas trabalhadas nos exercícios propostos, inclusive trocando observações com os colegas a respeito do enredo das mesmas.

A turma da escola intitulada WT, que se dispôs a participar de forma voluntária em horário extraturno, contou com a participação de quase $100 \%$ dos estudantes em todas as aulas, sempre questionando o assunto que seria abordado na aula seguinte e, se também seria usada uma HQ para abordagem do próximo tema. Nesse sentido, os estudantes indicaram que, se as aulas de ciências fossem trabalhadas com o uso dessa ferramenta, ficariam mais atrativas e possibilitariam uma forma mais fácil de aprendizagem, pois o uso de imagens facilitaria esse processo. 
Conclui-se que novas ferramentas para o ensino de Astronomia constituem um diferencial positivo no processo de ensino-aprendizagem. No caso das HQs como ferramentas de ensino, estas podem promover um fator motivacional muito sensível aos estudantes envolvidos no processo de aprendizagem em ciências, particularmente a aprendizagem de conceitos de Astronomia.

\section{Reierências}

Amaral, P. (2008). O ensino de Astronomia nas séries finais do ensino fundamental: uma proposta de material didático de apoio ao professor. Dissertação. Programa de Pós-graduação em Ensino de Ciências. Universidade de Brasília, Brasília, DF, 2008. $102 \mathrm{f}$. Disponível em: https://repositorio.unb.br/bitstream/10482/2517/1/2008_PatriciaAmaral.pdf Acesso 15 nov. 2018.

Brasil. Ministério da Educação (2018). Base Nacional Comum Curricular. Educação é a base, 2018. Disponível em: http://basenacionalcomum.mec.gov.br/images/BNCC_EI_EF_110518_versaofinal_site.pdf Acesso 18 jun. 2019.

Bonfleur, R. C., Scalabrin, M. H., Emílio, M., \& Cardoso, L. M. (2007). Astrônomo júnior. Ponta Grossa [PR] : Universidade Estadual de Ponta Grossa.

Carvalho et al. (2009). Os quadrinhos nas aulas de ciências naturais: uma história que não está no gibi. Revista Educação em Questão, 35 (21), pp.120-145, maio/ago. 2009. Natal [RN] Brasil.

Palhares, M. C. (2008). História em Quadrinhos: Uma Ferramenta Pedagógica para o Ensino de História. Programa de Desenvolvimento Educacional (PDE), 2008. Disponível em: http://www.diaadiaeducacao.pr.gov.br/portals/pde/arquivos/2262-8.pdf Acesso 31 out. 2018.

Massuda, E. A. (2011). História em quadrinhos: estímulo e lições de cidadania no projeto de formação de Tweens do Johrei Center Barretos. Brasília [DF] : Universidade Aberta do Brasil, Universidade de Brasília. Disponível em: https://bdm.unb.br/bitstream/10483/4456/1/2011_ElianaAkemiMasuda.pdf Acesso 30 out. 2018.

Milone et al. (2018). Introdução à Astronomia e Astrofísica. São José dos Campos [SP] : INPE. [Brasil. Ministério da Ciência e Tecnologia. INPE-7177-PUD/38].

Testoni, L. A. (2004). Um corpo que cai: As Histórias em Quadrinhos no Ensino de Física. 2004. 157 f. Dissertação (Mestrado) Curso de Educação, Universidade de São Paulo, São Paulo [SP] Brasil. Disponível em:

https://www.teses.usp.br/teses/disponiveis/48/48134/tde-28032014-

113618/publico/LEONARDO_ANDRE_TESTONI.pdf Acesso: 01 nov. 2018. 